Nissim-Sabat, D. (1979). The teaching of abnormal psychology through the cinema. Teaching of Psychology, 6, 121-123.

Phillips, M., Phillips, J. (Producers), \& Scorsese, M. (Director). (1976). Taxi driver [Film]. Burbank, CA: Columbia.

Streisand, B. (Producer), \& Ritt, M. (Director). (1987). Nuts [Film]. Hollywood, CA: Warner Brothers.

Tversky, A., \& Kahneman, D. (1974). Judgment under uncertainty: Heuristics and biases. Science, 185, 1124-1131.
Notes

1. I thank Ruth L. Ault, three anonymous reviewers, and Amy Gervasio for their helpful comments on earlier drafts of this article.

2. Requests for reprints should be sent to Dana D. Anderson, Department of Psychology, Pacific Lutheran University, Tacoma, WA 98447-0003.

\title{
Making TV Commercials as a Teaching Aid for Cognitive Psychology
}

\author{
Scott D. Gronlund \\ Stephan Lewandowsky \\ University of Oklahoma
}

Many students approach psychology in general, and cognitive psychology in particular, with serious misconceptions about the scientific nature of the discipline. In order to address this problem and bring laboratory findings in cognitive psychology into a realworld context, we asked students in an introductory cognitive course to make TV commercials using principles learned in class. The success of the approach became evident from analysis of course evaluation forms and the generally high quality of students' productions.

One of the problems facing teachers of experimental psychology is not that they must teach a science to nonmajors but, paradoxically, that they have to teach a science to majors. Students preparing to major in chemistry, physics, or any other hard science know to take plenty of math and science courses in high school and expect to continue taking these courses in college. Unfortunately, there is a widespread misconception that psychology, although acknowledged to be a science, relies less on computer literacy, quantitative skills, or methodological sophistication than do other fields. In reality, many areas of psychology require training as a scientist in much the same way as does chemistry or physics.

Psychology instructors have to contend with majors who are intimidated by introductory statistics courses and see little connection between abstract laboratory experiments and their daily experiences. We have found that the latter problem can be addressed by getting students involved in the design and production of TV commercials.

Parallels to our approach can be found in Stahl's (1991) call for increased involvement of undergraduates in the subject matter of a discipline and, more specifically, in Labianca's (1991) use of TV in the teaching of toxicology to nonscience majors. Labianca used detective shows to enhance students' interest in toxicology. For example, in an episode of "Murder, She Wrote," atropine is used as a chemical weapon. Throughout the episode, students learn about the symptoms of atropine poisoning and its treatment. By requiring the creation of an episode from scratch, our use of TV commetcials takes student involvement one step further.

\section{Background}

We are cognitive psychologists responsible for a juniorlevel introductory course in human memory and cognition. Not satisfied with past attempts to motivate our students with the current set of cognitive textbooks, and reluctant to cover the standard set of laboratory-based findings in a lecture format, we tried to increase student interest and participation by asking our students to produce TV commercials using principles learned in lecture and in the textbook.

\section{Preparation of Commercials}

The major project in the course was to design, script, film, and defend orally a 2-to 3-min TV commercial for some fictitious product or service. Students worked in small groups of approximately 4 to 5 , randomly formed at the beginning of the semester. Each of the 12 groups met with the instructor two or more times during the semester to discuss ideas for the commercial, the cognitive principles to be illustrated, and other relevant details.

Students met outside of class to film their commercials. Although camcorders could have been made available through the university, each group had access to its own 
recording device. With the prevalence of camcorders today, lack of equipment or facilities is unlikely to restrict use of this teaching tool.

Toward the end of the semester, on two special "commercial days," each group screened its commercial, followed by an oral cognitive analysis. The instructors and an additional faculty member not familiar with these students served as judges, conferring special recognition for best production, best actor/actress, best sound effects, best illustration of a cognitive principle, and so forth. Half the grade points for all students in a given group were based on the judgments by faculty, and the remaining grade points for an individual were assigned anonymously by the other group members, thus giving equal weighting to group and individual performance. Although grading by peers is known to identify students who did not fully participate in a group project (Michaelsen, Watson, \& Shrader, 1985), among our 12 groups only 1 such student was identified. Overall, the commercial accounted for $20 \%$ of the course grade.

\section{Evaluation by Students}

We augmented the standard end-of-semester course evaluations with 10 additional questions that students rated on a scale ranging from strongly agree (1) to strongly disagree (5). Three of these questions concerned the commercials. Most students $(86 \%)$ strongly agreed with "I enjoyed watching the commercials," $80 \%$ strongly agreed or agreed with "I enjoyed making my commercial," and $46 \%$ strongly agreed or agreed with "Making my commercial helped me better understand the course material."

A comparison with the remaining items, which questioned the utility of other teaching tools, helps put the role of the TV commercial in perspective. Students had to (a) keep a journal of everyday experiences relevant to the course material, (b) complete a library project to become more familiar with various literature-research tools (Psychological Abstracts, Social Sciences Citation Index, etc.), and (c) read classic articles from the literature to supplement the text. Table 1 shows the distribution of responses to the question "Doing . . . helped me better understand the course material" for each of these teaching tools.

It is apparent from Table 1 that students considered the TV commercial to be a superior teaching tool in comparison to the other components of this course: Only $16 \%$ of the respondents disagreed with the assertion that the commercial was helpful, whereas $43 \%$ of respondents disagreed with

Table 1. Percentage of Responses to Questions Concerning Better Understanding of Course Material

\begin{tabular}{lcccc}
\hline & \multicolumn{4}{c}{ Teaching Tool } \\
\cline { 2 - 5 } Response & TV & Library & & \\
\hline Strongly agree & Commercial & Project & Journal & Readings \\
Agree & 20 & 10 & 0 & 6 \\
Neutral & 26 & 23 & 30 & 13 \\
Disagree & 36 & 16 & 26 & 20 \\
Strongly disagree & 6 & 10 & 23 & 33 \\
\hline
\end{tabular}

the utility of the journals. This is noteworthy because journals form part of the standard repertory of teaching devices (e.g., Svinicki \& Dixon, 1987). Similarly, 59\% of the students did not feel that the inclusion of classic articles from the literature in their reading list was beneficial, and $50 \%$ saw little merit in the library project.

Another way of summarizing these data is by comparing the mean response across teaching tools. The commercial $(M=2.65)$ is distinguishable from the library project (3.32), the journal (3.26), and the extra readings (3.55). A one-way within-subjects analysis of variance for the 31 respondents confirmed that the differences between those means were significant, $F(3,90)=4.05, p<.01$. A Newman-Keuls multiple comparison test (at the .05 level) established that the TV commercial was judged more favorable than the other three teaching tools, which did not differ from each other.

Although these results demonstrate that students held the commercials in higher regard than the other projects, the questionnaire cannot reveal the extent of learning or the potential gain in knowledge resulting from the commercials. One way to assess these potential gains is by analyzing the oral presentations that accompanied each commercial.

\section{Evaluation by Instructors}

The instructors and the third faculty member present at the commercial screenings recorded the cognitive principles that students included in their oral presentations. Principles are included in the following list only if students explained them correctly and if they were indeed used in the commercial. That way we do not include principles that students used accidentally, simply by copying features of actual commercials.

\section{Chunking}

Virtually every commercial relied heavily on chunking (Miller, 1957) to make phone numbers and the like more memorable (e.g., 1-800-CHEATIN).

\section{Primacy and Recency}

All groups placed important parts of the message at the beginning and end of the commercial, thus maximizing the probability of retention by exploiting primacy and recency effects (e.g., Glanzer, 1972). In addition, most commercials ended on a spoken repetition (as opposed to visual display) of the product name or the key message, in line with the fact that recency is greater with auditory than visual presentation (e.g., Crowder, 1972).

\section{Repetition}

Important parts of the commercials' messages were usually repeated, and most groups took into account the spacing effect (e.g., Hintzman, 1974), which shows that repetitions 
are most effective in improving memory when they are spaced apart with other material intervening. Thus, one group interspersed pricing information and further product details between repetitions of a telephone number.

\section{Rehearsal}

One group intended to induce rehearsal of the key message, which remained ambiguous for most of the commercial. The commercial featured several people who described recent predicaments in their lives (e.g., unemployment and delayed child-support payments), always concluding their sad story by sighing, "we'll see." In the end, this commercial turned out to advertise the services of one Will C. Gates, attorney.

\section{Depth of Processing}

Several commercials attempted to induce deep or elaborative processing of the message (Craik \& Lockhart, 1972). Thus, one commercial engaged the viewer in disambiguating a homophone during presentation (e.g., waste vs. waist) that later formed part of a phone number (1-800-NOWAIST).

\section{Cue-Dependence}

To encourage memory of the product name, several groups presented it with potentially effective retrieval cues (e.g., the title music of the film Ghostbusters or some of Strauss's music from 2001). The groups claimed that this technique would later help reinstate awareness of their product when the viewer heard the corresponding music.

\section{Experimentation}

One commercial, produced by a single individual, was pretested by true experimentation. The commercial advertised a children's soup, and the subjects were elementary school children who had to memorize and then pronounce various potential product names. The results pointed to "Mutant Ninja Turtle Soup" as the optimal name for the product, and the commercial then consisted of a series of these children walking up to the camera, trying to pronounce the product name as quickly as possible.

\section{Conclusion}

The consensus among the attending faculty members was that the quality of students' productions generally was very high. Numerous reasons for this apparent success can be cited. First, all the commercials were humorous, which not only made the productions fun to watch but no doubt also fun to produce, thus ensuring active participation by all group members. Second, because nearly everyone is an expert on commercials, having seen thousands, all students can offer ideas for design and scripting. Third, as shown by the analysis of oral presentations, students could extract principles from a typical textbook and apply them to the production of commercials. Although some of the cognitive aspects outlined earlier may not survive empirical scrutiny (e.g., if memorability were compared to an explicitly noncognitive commercial), there is little doubt that students were able to apply textbook knowledge to a practical problem in a creative fashion.

\section{References}

Craik, F. I. M., \& Lockhart, R. S. (1972). Levels of processing: A framework for memory research. Journal of Verbal Learning and Verbal Behavior, 11, 671-684.

Crowder, R. G. (1972). Visual and auditory memory. In J. F. Kavanaugh \& I. G. Mattingly (Eds.), Language by ear and by eye: The relationships between speech and reading (pp. 251-276). Cambridge, MA: MIT Press.

Glanzer, M. (1972). Storage mechanisms in recall. In G. H. Bower \& J. T. Spence (Eds.), The psychology of learning and motivation (Vol. 5, pp. 129-193). New York: Academic.

Hintzman, D. L. (1974). Theoretical implications of the spacing effect. In R. L. Solso (Ed.), Theories in cognitive psychology: The Loyola symposium (pp. 77-99). Hillsdale, NJ: Lawrence Erlbaum Associates, Inc.

Labianca, D. A. (1991). Toxicology for nonscience majors: Using TV. College Teaching, 39, 100-104.

Michaelsen, L. K., Watson, W. E., \& Shrader, C. B. (1985). Informative testing: A practical approach for tutoring with groups. The Organizational Behavior Teaching Review, 9, 18-33.

Miller, G. A. (1957). The magical number seven plus or minus two: Some limits on our capacity for processing information. Psychological Review, 63, 81-97.

Stahl, F. A. (1991). Research and teaching: Partnership, not paradox. College Teaching, 39, 97-99.

Svinicki, M. D., \& Dixon, N. M. (1987). The Kolb model modified for classroom activities. College Teaching, 35, 141-146.

\section{Note}

Requests for reprints should be sent to Scott D. Gronlund, Department of Psychology, University of Oklahoma, Norman, OK 73019-0535 (e-mail: scott@comedy.psy.uoknor.edu). 